\title{
PERCEPÇÃO SOBRE A CARREIRA DE CONTABILIDADE SOB A ÓTICA DE PROFESSORES DO ENSINO MÉDIO
}

$\begin{array}{ll}\text { Nome } & \text { Claudio de Souza Miranda } \\ \begin{array}{l}\text { Instituição/Afiliação } \\ \text { País }\end{array} & \begin{array}{l}\text { FEARP-USP } \\ \text { Resumo da } \\ \text { Biografia }\end{array} \\ & \begin{array}{l}\text { Docente do Departamento de Contabilidade da FEARP-USP } \\ \text { Nome }\end{array} \\ \begin{array}{l}\text { Instituição/Afiliação } \\ \text { País }\end{array} & \begin{array}{l}\text { Universidade Paulista } \\ \text { Resumo da }\end{array} \\ \text { Biografia } & \text { Brasil } \\ \end{array}$

\section{RESUMO}

Estudos demonstram que professores de ensino médio tem participação significativa na tomada de decisão dos alunos com relação a escolha de carreira. Os estudos de Sugahara, Kurihara e Boland (2006), Hardin, O’Bryan e Quirin (2000) e Wells e Fieger (2004) demonstraram que os professores ainda não compreendem a natureza e a importância da profissão contábil. $\mathrm{O}$ presente trabalho buscou analisar a percepção dos professores de ensino médio no Brasil acerca da carreira contábil em comparação com as carreiras de medicina, engenharia e advocacia. $\mathrm{O}$ trabalho foi desenvolvido por meio de um levantamento para medir a percepção de professores de ensino médio no Brasil. Com base na comparação com as outras profissões a contabilidade teve a menor avaliação, corroborando os resultados já encontrados nos estudos anteriores.

Palavras chave: percepção de professores de ensino médio, Escolha de carreira, Carreira contábil

\section{INTRODUÇÃO}

O curso de Ciências Contábeis apesar de estar presente no país oficialmente a partir da década de 40, já tinha conteúdo proposto desde o século XIX nas aulas de comércio. Segundo Peleias (2006), as aulas de comércio continham disciplinas de natureza prática, dirigidas às necessidades diárias do comércio e dos negócios bancários. Essas atividades demandavam instrumentos de gestão mais precisos existentes na Contabilidade da época.

O Censo do Ensino Superior do Brasil de 2016, disponível no Instituto Nacional de Estudos e Pesquisas Educacionais (INEP, 2017) indica que nos últimos anos, o curso de Ciências Contábeis é $5^{\circ}$ curso em número de matrículas, entre os cursos presenciais e a distância. Em 2016, existiam 1.164 autorizações para a o curso de Ciências Contábeis, tendo 355.425 alunos matriculados na modalidade presencial e a distância. Soma-se a isso a informação do Conselho Federal de Contabilidade que indica em novembro de 2018 que haviam 351 mil contadores cadastrados.

Esse número sinaliza demanda para a profissão. Entretanto, em alguns países, como por exemplo, os Estados Unidos, a procura pela profissão tem decrescido nos últimos anos. O estudo de Albrecht e Sack (2000) demonstra por meio de dados do American Institute of Certified Public Accountants (AICPA), órgão responsável pela certificação pública de contadores, que a demanda pela certificação de contador tem diminuído, e aponta como principais motivos para esta redução, os seguintes fatores: baixos salários iniciais se comparada 
a outras carreiras ligadas a negócios, alternativas mais atraentes, e em função de falta de informações ou informações distorcidas acerca da profissão. O estudo do AICPA aponta que parte disto é responsabilidade de professores de Contabilidade nas escolas e universidades que desenvolvem as atividades relacionadas à profissão, mais voltadas para o aspecto do "bookkeeping" (guarda livros).

A profissão da contabilidade muitas vezes tem sua visão rebaixada em função de escândalos e fraudes onde o profissional contábil esteja envolvido, assim como os casos da Enron, Worldcom, Xerox, entre outras. Pesquisa realizada por Coleman, Kreuze e Langsam (2004), aponta que estudantes entendem que continuam achando a contabilidade uma profissão honorável, apesar dos escândalos, embora tenha se tornado menos atrativa. No Brasil também se teve casos de fraudes contábeis como o caso do Banco Panamericano, em 2010, isso pode de alguma forma influenciar a opinião da sociedade brasileira sobre a contabilidade de uma forma negativa.

$\mathrm{Na}$ literatura são observados alguns estudos sobre a percepção da população, em diversos extratos, sobre a profissão contábil. Segundo Costa (2010), a percepção, embora tenha uma definição voltada aos órgãos dos sentidos, ou seja, para a interpretação, é considerada pela psicologia para os estudos de comportamento, pois o comportamento das pessoas é baseado na interpretação que fazem da realidade e não na realidade em si.

Uma das categorias de estudos encontradas na literatura são estudos sobre a percepção da profissão contábil na visão de professores de segundo grau. A avaliação deste extrato especificamente é interessante, visto que diversos outros estudos apontam a importância que este profissional tem na tomada de decisão da carreira dos estudantes. Segundo Sugahara, Kurihara e Boland (2006), há uma grande possibilidade de que os professores de ensino médio possam encorajar os melhores alunos a ingressar a profissão contábil, desde que eles possuam uma imagem positiva desta profissão.

Byrne e Willis (2005) encontraram como resultado do estudo feito na Irlanda, que os principais fatores de influência na percepção dos alunos do ensino médio sobre a contabilidade foram o estudo da matéria no ensino médio, a imprensa e os seus professores. O estudo de Miranda, Miranda e Araújo (2013) com estudantes de segundo grau no Brasil, indica que as principais fontes de informação sobre uma carreira são obtidas pelos estudantes por meio da Internet (73\%) e junto a seus professores $(60 \%)$.

O International Federation of Accountants (IFAC) tem como visão: a contabilidade sendo uma profissão reconhecida globalmente como uma valiosa liderança no desenvolvimento de organizações e mercados financeiros sustentáveis e de fortes economias internacionais, mas não é o que está acontecendo atualmente. A percepção da contabilidade acaba se tornando uma fonte de preocupação, por ser considerada equivocada e estereotipada negativamente (AZEVEDO, 2010), devido em grande parte ao desconhecimento das atividades profissão por parte dos não-contadores.

De acordo com o estudo de Pekdemir e Pekdemir (2010), feito com professores do Ensino Médio da Turquia, grande parte dos professores que participaram do estudo não tinha ideia e opiniões muito claras sobre a profissão contábil e 37,7\% deles não deram nenhuma opinião sobre o nível de importância da profissão. Este estudo ainda mostra que a maior parte dos respondentes não tinha ideia de onde vieram as suas opiniões sobre a contabilidade ou como eles chegaram até elas, sendo que $77,6 \%$ deles disseram que a opinião deles foi influenciada pela imprensa e pela mídia.

Albrecht e Sack (2000) sugerem que as ideias equivocadas sobre as atividades e o papel dos profissionais contábeis são causadas por quatro fatores: falta de entendimento sobre a carreira de contabilidade por parte dos professores de ensino médio e orientadores vocacionais; uma incompatibilidade entre as habilidades percebidas e as habilidades realmente necessárias para a carreira de contabilidade; a ênfase no aspecto de escrituração nas matérias de 
contabilidade para o ensino médio; e uma visão estreita, focada no mero atingimento de metas nos cursos de graduação em contabilidade.

Segundo Sugahara, Kurihara e Boland (2006), os melhores alunos do Japão continuariam sendo orientados para outras profissões que não a contabilidade, porque os professores do ensino médio ainda não compreendem a natureza e a importância da profissão contábil.

No caso brasileiro, Azevedo (2010) afirma que durante o processo de entrevistas, realizado na cidade de São Paulo, notou que a população em grande parte acaba vinculando a contabilidade como um curso de ciências exatas, o que não reflete as características de uma ciência social aplicada, área a qual a contabilidade está de fato. Essa situação também foi encontrada por Miranda, Araújo e Miranda (2012) em investigação com mais de 6.600 pessoas com nível superior ou em curso ao avaliar suas percepções sobre a contabilidade, soma-se a isso a percepção geral de ser uma atividade técnica ligada principalmente a questões legais/fiscais.

Em partes, esse desconhecimento em relação à atuação do profissional contábil pode ser explicado pelas mudanças na natureza do trabalho de contabilidade, que incorporou altos níveis de envolvimento com os clientes, complexas tecnologias e o aparecimento de sofisticados instrumentos financeiros, que aumentaram a pressão sobre os profissionais de contabilidade, necessitando a profissão agora de estudantes com capacidade de lidar com uma grande variedade de técnicas, incluindo uma habilidade de análise bem desenvolvida e flexibilidade para se adaptar às mudanças no ambiente de trabalho. (MCDOWALL, T.; JACKLING, B.; NATOLI, R. 2010)

Hardin, O’Bryan e Quirin (2000) fizeram uma análise estatística das percepções dos professores do ensino médio dos Estados Unidos sobre a contabilidade, a pesquisa foi efetuada com 128 professores. Foi pedido aos respondentes que avaliassem 24 atributos profissionais numa escala de 1 a 100, com os resultados indicando que os professores de ensino médio tinham uma percepção ligeiramente pior da contabilidade em comparação com a engenharia, o direito e a medicina.

Wells e Fieger (2004) conduziram um estudo similar na Nova Zelândia, com 36 professores, e os resultados obtidos indicam que os professores do ensino médio da Nova Zelândia também têm uma percepção pior da contabilidade em relação às outras profissões. Enquanto os estudos feitos nos Estados Unidos e Nova Zelândia sugerem que os professores de ensino médio possuem uma opinião relativamente pior sobre a contabilidade quando comparada com as outras três profissões, no Japão a percepção dos professores foi relativamente pior do que direito e medicina, mas um pouco melhor do que engenharia, o que pode ser explicado em parte pelo fato da engenharia, no Japão, ser uma profissão que não exige certificação. (SUGAHARA; KURIHARA; BOLAND et al. 2006). O estudo no Japão foi efetuado com 87 professores.

Estudos como os de Hardin, O’Bryan e Quirin (2000), Wells e Fieger (2004) e Sugahara, Kurihara e Boland (2006), com a intenção de avaliar as percepções dos professores sobre a profissão contábil não são observados no Brasil. Como observado existem apenas avaliações sobre a população em geral ou de estudantes de segundo grau.

Neste sentido essa pesquisa buscou avaliar a percepção de professores do ensino médio sobre a profissão contábil, com foco principal no estado de São Paulo. A avaliação foi desenvolvida com base nos estudos anteriores avaliados.

Como objetivos secundários esta pesquisa buscou avaliar se há diferenças de percepções dos docentes em função de características pessoais como: nível de conhecimento das carreiras; perfil da escola que ministra aulas, e ainda se há diferenças de percepção do docentes brasileiros com os estudos anteriores. 


\section{METODOLOGIA}

Com intuito de comparar a percepção dos professores de ensino médio sobre a profissão do contador, médico, engenheiro e advogado e cumprir com o objetivo proposto para o trabalho, foi desenvolvido um questionário baseado nos atributos contidos nos trabalhos sobre a indicação de profissões feita por professores aos alunos, baseado nos trabalhos de Hardin, O’Bryan e Quirin (2000), Wells e Fieger (2004) e Sugahara, Kurihara e Boland (2006). Os atributos definidos encontram-se no quadro 1.

Quadro 1- Atributos de uma profissão

\begin{tabular}{|l|}
\hline Esse profissional possui um alto status na sociedade \\
\hline Esse profissional é essencial para a sociedade \\
\hline Esse profissional ocupa uma posição de poder na sociedade \\
\hline Esse profissional ocupa uma posição de glamour/destaque na sociedade \\
\hline Essa carreira oferece potencial para o profissional ganhar muito dinheiro \\
\hline O candidato encontra muita dificuldade para ingressar nessa carreira \\
\hline Essa carreira oferece ótimas oportunidades de trabalho \\
\hline Essa carreira oferece um grande potencial de crescimento ao profissional \\
\hline Essa carreira oferece um grande potencial de crescimento para mulheres \\
\hline Essa carreira é indicada para os melhores alunos \\
\hline Esse profissional possui um alto nível de ética \\
\hline Essa carreira é dominada por homens \\
\hline O trabalho nessa profissão é muito desafiante \\
\hline Esse profissional interage bastante com outras pessoas \\
\hline Essa carreira proporciona uma grande satisfação na realização dos trabalhos \\
\hline Esse profissional está propenso a cometer ações fraudulentas \\
\hline Esse profissional possui uma grande habilidade de comunicação \\
\hline Esse profissional possui uma grande habilidade para resolver problemas \\
\hline Esse profissional possui uma grande habilidade com números \\
\hline Essa carreira proporciona um bom estilo de vida \\
\hline Essa carreira proporciona uma boa vida familiar \\
\hline $\begin{array}{l}\text { Essa carreira exige muitas horas de trabalho, tendo o profissional que fazer horas extras, trabalhar de fim de semana, } \\
\text { etc... }\end{array}$ \\
\hline Essa carreira oferece estabilidade no emprego \\
\hline O trabalho desempenhado nesta profissão é muito interessante \\
\hline Fonte: Adaptado de Hardin, O'Bryan e Quirin (2000), Wells e Fieger (2004) Sugahara, Kurihara \\
\hline
\end{tabular}

Fonte: Adaptado de Hardin, O’Bryan e Quirin (2000), Wells e Fieger (2004) Sugahara, Kurihara e Boland (2006)

Para cada um dos atributos, solicitou-se aos professores que dessem uma nota de 1 a 4 , de menor (1) a maior concordância (4), para cada uma das profissões (Direito, Engenharia, Contabilidade e Medicina). Esta categorização é a mesma atribuída no trabalho de Sugahara, Kurihara e Boland (2006).

O modelo de pesquisa utilizado é quantitativo, buscando obter entendimento acerca da percepção dos professores do ensino médio sobre determinadas profissões, principalmente, no estado de São Paulo.

O método de desenvolvimento da pesquisa é o levantamento que segundo Callegaro, Manfreda e Vehovar (2015) diz respeito a um método de coleta sistemática de dados, por meio de questionários, com a finalidade de analisar quantitativamente algum público-alvo, que é a população de interesse da pesquisa.

Especificamente este levantamento foi uma Websurvey que de acordo com Umbach (2004) trata-se de levantamento efetuado via internet. Segundo Callegaro et al (2015) as websurveys são basicamente levantamentos com certas especificidades, de modo geral utiliza os mesmos princípios metodológicos dos levantamentos. Este processo facilita a obtenção de um maior número de respondentes, além de reduzir custos de pesquisas tradicionais, como: 
correio, papel, e telefone, bem como evita o dispêndio de tempo de resposta e no processo de tabulação, além de evitar erros de entrada de dados.

Alguns pontos negativos da websurvey de acordo com Dilmann (2000) são o fato de o respondente não ter acesso eletrônico, ou mesmo de se conseguir os endereços eletrônicos da população almejada. No caso desta pesquisa, estes aspectos foram superados pelo fato de ser um público com perfil de acesso a meios eletrônicos e, também, pelo fato de haver meios para coleta dos contatos da população estudada.

A população objeto da pesquisa foram os professores de ensino médio, principalmente do estado de São Paulo de escolas particulares e públicas. Para este projeto, entrou-se em contato com 56 escolas e delegacias de ensino, em uma amostra por conveniência em função de facilidade de acesso, e solicitou-se o contato (e-mail) dos professores, para os quais foram enviados o questionário a todos os professores em que se recebeu o feedback com o e-mail. $\mathrm{O}$ retorno obtido foi de 147 contatos de professores.

\section{CARACTERIZAÇÃO DA AMOSTRA}

O questionário foi enviado via e-mail aos 147 professores, o número de questionários respondidos e válidos foi de 63 (sessenta e três) o que dá uma taxa de resposta de $43 \%$. Obtevese respostas de professores de 10 diferentes cidades, tanto do interior quando da região metropolitana de São Paulo. As principais características da amostra estão expostas na tabela 1

Os dados da tabela 1 demonstram uma maior concentração de docentes do sexo feminino, de escola pública e com atuação principalmente em disciplinas da área de humanas. Em termos de idade e tempo de docência não há concentrações na amostra da pesquisa.

Tabela 1- Perfil dos respondentes

\begin{tabular}{|c|c|c|}
\hline Gênero dos respondentes & Quantidade & Percentual \\
\hline Gênero masculino & 21 & $33 \%$ \\
\hline Gênero feminino & 42 & $67 \%$ \\
\hline Tipo de colégio & Quantidade & Percentual \\
\hline Particular & 13 & $21 \%$ \\
\hline Pública & 44 & $70 \%$ \\
\hline Ambos & 6 & $10 \%$ \\
\hline Idade & Quantidade & Percentual \\
\hline 20 a 30 anos & 22 & $35 \%$ \\
\hline 31 a 50 anos & 28 & $44 \%$ \\
\hline 51 a mais de 60 anos & 13 & $21 \%$ \\
\hline Tempo de docência & Quantidade & Percentual \\
\hline 1 a 5 anos & 17 & $27 \%$ \\
\hline 6 a 10 anos & 11 & $18 \%$ \\
\hline 11 a 15 anos & 11 & $18 \%$ \\
\hline 16 a 25 anos & 19 & $30 \%$ \\
\hline Mais de 25 anos & 5 & $8 \%$ \\
\hline Área de atuação & Quantidade & Percentual \\
\hline Exatas & 15 & $24 \%$ \\
\hline Humanas & 40 & $64 \%$ \\
\hline Biológicas & 8 & $13 \%$ \\
\hline
\end{tabular}

Fonte: Dados da pesquisa. 


\section{RESULTADOS}

Assim como nos estudos de Wells e Fieger (2004) e de Sugahara, Kurihara e Boland (2006) a primeira análise dos dados utilizou-se médias aritméticas das respostas obtidas e comparou-se entre as 4 profissões analisadas (contador, médico, advogado e engenheiro), focando na comparação entre a profissão contábil e as demais. Também se efetuou uma análise de teste de médias (Friedman) para avaliar se havia diferença entre os grupos.

A tabela 2 à seguir apresenta os resultados em seis subseções, a primeira apresenta os resultados dos atributos onde a contabilidade foi significativamente diferente de engenharia, direito e medicina. As próximas seções mostraram os atributos onde a contabilidade foi significativamente diferente de um ou mais dos outros profissionais, finalmente os atributos que a contabilidade foi supeior às demais profissões.

Tabela 2 - Notas médias dos atributos

Atributos em que a contabilidade possuiu pior avaliação que as demais.

\begin{tabular}{|c|c|c|c|c|c|}
\hline & $\underline{\mathrm{ADV}}$ & $\underline{\text { ENG }}$ & CONT & $\underline{\text { MED }}$ & $\begin{array}{l}\text { Diferença } \\
\text { Significativa } \\
\end{array}$ \\
\hline Esse profissional possui um alto status na sociedade & 3,18 & 3,35 & 2,39 & 3,67 & Sim \\
\hline Esse profissional é essencial para a sociedade & 3,61 & 3,84 & 3,26 & 3,93 & Sim \\
\hline Esse profissional ocupa uma posição de poder na sociedade & 3,23 & 2,84 & 2,28 & 3,46 & Sim \\
\hline $\begin{array}{l}\text { Esse profissional ocupa uma posição de glamour/destaque na } \\
\text { sociedade }\end{array}$ & 3,12 & 3,21 & 2,21 & 3,77 & Sim \\
\hline $\begin{array}{l}\text { Essa carreira oferece potencial para o profissional ganhar muito } \\
\text { dinheiro }\end{array}$ & 3,26 & 3,42 & 2,75 & 3,63 & Sim \\
\hline $\begin{array}{l}\text { O candidato encontra muita dificuldade para ingressar nessa } \\
\text { carreira }\end{array}$ & 3,02 & 3,02 & 2,25 & 3,18 & Sim \\
\hline Essa carreira oferece ótimas oportunidades de trabalho & 3,23 & 3,56 & 2,81 & 3,62 & Sim \\
\hline $\begin{array}{l}\text { Essa carreira oferece um grande potencial de crescimento ao } \\
\text { profissional }\end{array}$ & 3,4 & 3,63 & 3,05 & 3,61 & Sim \\
\hline $\begin{array}{l}\text { Essa carreira oferece um grande potencial de crescimento para } \\
\text { mulheres }\end{array}$ & 3,25 & 3,23 & 3,02 & 3,6 & Sim \\
\hline Essa carreira é indicada para os melhores alunos & 2,81 & 3,16 & 2,61 & 3,28 & Sim \\
\hline O trabalho nessa profissão é muito desafiante & 3,47 & 3,58 & 2,63 & 3,65 & Sim \\
\hline Esse profissional interage bastante com outras pessoas & 3,84 & 3,21 & 3,02 & 3,84 & Sim \\
\hline $\begin{array}{l}\text { Essa carreira proporciona uma grande satisfação na realização } \\
\text { dos trabalhos }\end{array}$ & 3,32 & 3,52 & 3,1 & 3,51 & Sim \\
\hline $\begin{array}{l}\text { Esse profissional possui uma grande habilidade para resolver } \\
\text { problemas }\end{array}$ & 3,59 & 3,6 & 3,35 & 3,56 & Não \\
\hline Essa carreira proporciona um bom estilo de vida & 3,22 & 3,29 & 2,86 & 3,41 & Sim \\
\hline $\begin{array}{l}\text { Essa carreira exige muitas horas de trabalho, tendo o profissional } \\
\text { que fazer horas extras, trabalhar de fim de semana, etc }\end{array}$ & 3,25 & 3,1 & 2,81 & 3,76 & Sim \\
\hline O trabalho desempenhado nesta profissão é muito interessante & 3,54 & 3,7 & 3,08 & 3,75 & Sim \\
\hline
\end{tabular}

Atributo em que a contabilidade possuiu avaliação abaixo de advocacia e medicina, mas superior à engenharia.

\begin{tabular}{l|c|c|c|c|c}
\hline & $\underline{\text { ADV }}$ & $\underline{\text { ENG }}$ & $\underline{\text { CONT }}$ & $\underline{\text { MED }}$ & $\begin{array}{c}\text { Diferenca } \\
\text { Significativa }\end{array}$ \\
\hline Esse profissional possui uma grande habilidade de comunicação & 3,79 & 2,71 & 2,87 & 3,17 & Sim \\
\hline
\end{tabular}

Atributos em que a contabilidade possuiu avaliação pior que engenharia, mas superior à advocacia $\mathrm{e}$ medicina. 


\begin{tabular}{l|c|c|c|c|c|c} 
& $\underline{\text { ADV }}$ & $\underline{\mathbf{E N G}}$ & $\underline{\mathbf{C O N T}}$ & $\underline{\mathbf{M E D}}$ & $\begin{array}{c}\text { Diferença } \\
\text { Significativa }\end{array}$ \\
\hline Essa carreira é dominada por homens & 2,49 & 3,26 & 2,79 & 2,39 & Sim \\
\hline Essa carreira proporciona uma boa vida familiar & 3,19 & 3,32 & 3,29 & 2,95 & Sim \\
\hline
\end{tabular}

Atributo em que a contabilidade possuiu avaliação pior que engenharia e medicina, mas superior à advocacia.

\begin{tabular}{l|c|c|c|c|c}
\hline & $\underline{\text { ADV }}$ & $\underline{\mathbf{E N G}}$ & $\underline{\underline{\text { CONT }}}$ & $\underline{\text { MED }}$ & $\begin{array}{c}\text { Diferenca } \\
\text { Significativa }\end{array}$ \\
\hline Essa carreira oferece estabilidade no emprego & 2,79 & 2,94 & 2,9 & 3,1 & Não \\
\hline Esse profissional possui um alto nível de ética & 2,65 & 3 & 2,79 & 2,96 & Não \\
\hline
\end{tabular}

Atributo em que a contabilidade possuiu avaliação pior que advocacia, mas superior à engenharia e a
medicina.

\begin{tabular}{l|c|c|c|c|c|c}
\hline \multicolumn{7}{c}{ Atributos em que a contabilidade possuiu melhor avaliação que as demais. } \\
\hline Esse profissional possui uma grande habilidade com números & $\underline{\text { ADV }}$ & $\underline{\underline{\mathbf{E N G}}}$ & $\underline{\underline{\text { CONT }}}$ & $\underline{\underline{\text { MED }}}$ & $\underline{\text { Diferenca }}$ \\
Significativa \\
\hline
\end{tabular}

Fonte: Dados da pesquisa.

Em 17 dos 24 atributos a profissão contábil foi considerada como menor importância que as outras 3 profissões, e em apenas uma não se encontrou diferença estatistica significativa pelo teste de Frideman. São tanto atributos ligados à questões sociais, de oportunidade de carreira, e de qualidade de vida no trabalho. Cabe ressaltar que em uma delas apesar de ser mais baixa, indica que a profissão não necessita de muitas horas extras e plantões de trabalho.

Em 16 dos 17 atributos em que a profissão contábil teve pior avaliaçaor, são observadas diferenças significativas entre os grupos de profissões, o que reforça grandes diferenças de avaliações. Apenas na questão de habilidade para resolução de problemas não foi observada diferença significativa.

Em apenas um atributo a contabilidade possuiu avaliação abaixo de advocacia e medicina, mas superior à engenharia. Este único atributo indicou que a profissão contábil foi considerada com necessidade de habilidade de comunicação superior a engenharia.

Em dois atributos a contabilidade possuiu avaliação pior que engenharia, mas superior à advocacia e medicina. Foram a indicação de que profissão é mais dominadas por homens e com mais qualidade de vida familiar.

Também em dois atributos a contabilidade possuiu avaliação pior que engenharia e medicina, mas superior à advocacia. No primeiro atributo observa-se que a profissão contábil foi considerada com mais estabilidade no emprego, e também foi observado que teve a segundo pior avaliação em termos de ser uma profissão com tendência a práticas fraudulentas. Cabe ressaltar que nestes dois atributos não são encontradas diferenças significativas de avalição entre as quatro profissões.

Em um atributo a contabilidade teve avaliação menor que a medicina e a engenharia e maior que o direito que seria o fato do profissional estar propenso a cometer ações fraudulentas. Este é um atributo negativo, em que a profissão juntamente com os advogados são os que tem piores percepções.

Em apenas um atributo a contabilidade foi percebida como superior a todas as outras profissões, que foi a habilidade quantitativa, mas que foi próxima a engenharia. Esta percepção 
estereotipada de que a profissão contábil tem relação direta com conhecimento matemáticos é observada em diversos estudos prévios analisados como os de Miranda, Miranda e Araújo (2013), Hunt et al (2004).

Parte dos resultados encontrados nas análises acima podem ser explicados pelo questionamento efetuado sobre indicação de carreiras. Solicitou-se aos professores uma nota de 1 a 10 para indicar o quanto eles indicaram as quatro profissões avaliadas aos seus alunos. Observa-se pela tabela 3 que a profissão contábil é a que tem menor indicação entre os docentes. Observa-se diferença estatística significativa entre as notas de indicação pelo teste de Friedman. Analisando-se as profissões em pares, apenas entre a indicação de contabilidade e direito não há diferença significativa.

Tabela 3- Indicação da carreira aos alunos

\begin{tabular}{|c|c|}
\hline Tabela 3- Indicação da carreira aos alunos \\
\hline Carreira & Média \\
\hline Contabilidade & 7,41 \\
\hline Advocacia & 7,63 \\
\hline Engenharia & 8,51 \\
\hline Medicina & 8,95 \\
\hline
\end{tabular}

Fonte: Dados da pesquisa.

Para avaliar se haveria diferenças de avaliação entre docentes do Brasil com os dos estudos anteriores, foi realizada uma comparação dos resultados encontrados no Brasil com os outros países conforme dados da tabela 4 a seguir, e a comparação demonstra percepções próximas em quase todas as variáveis em todos os países.

Como as notas de avaliação não foram iguais em todos os estudos, a comparação foi efetuada por meio de um "ranking" da posição em que cada profissão teve em cada uma das pesquisas anteriores. Assim, em cada uma das questões a profissão contábil poderia ter da maior nota de avaliação (representada pelo número 1 como sendo a melhor avaliação) até a pior nota (4). Nesta classificação não foi levada em consideração a existência ou não de diferenças significativas. O objetivo foi o de verificar se haveria semelhanças de percepções entre os docentes dos 4 países analisados.

Tabela 4 - Comparação com pesquisas anteriores

\begin{tabular}{|c|c|c|c|c|}
\hline Classificação da carreira (maior para a menor média) & Brasil & Japão & USA & NZ \\
\hline Esse profissional ocupa uma posição de glamour/destaque na sociedade & 4 & 4 & 4 & 4 \\
\hline Essa carreira oferece um grande potencial de crescimento ao profissional & 4 & 4 & 4 & 4 \\
\hline O trabalho nessa profissão é muito desafiante & 4 & 4 & 4 & 4 \\
\hline Essa carreira proporciona uma grande satisfação na realização dos trabalhos & 4 & 4 & 4 & 4 \\
\hline Esse profissional possui uma grande habilidade para resolver problemas & 4 & 4 & 4 & 4 \\
\hline $\begin{array}{l}\text { Essa carreira exige muitas horas de trabalho, tendo o profissional que fazer } \\
\text { horas extras, trabalhar de fim de semana, etc... }\end{array}$ & 4 & 4 & 4 & 4 \\
\hline O trabalho desempenhado nesta profissão é muito interessante & 4 & 4 & 4 & 4 \\
\hline Esse profissional possui um alto status na sociedade & 4 & 3 & 4 & 4 \\
\hline Esse profissional é essencial para a sociedade & 4 & 4 & 3 & 4 \\
\hline Esse profissional ocupa uma posição de poder na sociedade & 4 & 3 & 4 & 4 \\
\hline Essa carreira oferece potencial para o profissional ganhar muito dinheiro & 4 & 3 & 4 & 4 \\
\hline O candidato encontra muita dificuldade para ingressar nessa carreira & 4 & 3 & 4 & 4 \\
\hline Essa carreira é indicada para os melhores alunos & 4 & 3 & 4 & 4 \\
\hline Esse profissional interage bastante com outras pessoas & 4 & 3 & 4 & 4 \\
\hline Essa carreira é dominada por homens & 2 & 4 & 4 & 4 \\
\hline
\end{tabular}




\begin{tabular}{|l|r|r|r|r|}
\hline Esse profissional possui uma grande habilidade de comunicação & 3 & 3 & 4 & 4 \\
\hline Essa carreira proporciona um bom estilo de vida & 4 & 3 & 4 & 3 \\
\hline Essa carreira oferece estabilidade no emprego & 3 & 3 & 4 & 4 \\
\hline Essa carreira oferece ótimas oportunidades de trabalho & 4 & 2 & 4 & 3 \\
\hline Esse profissional está propenso a cometer ações fraudulentas & 2 & 3 & 4 & 4 \\
\hline Esse profissional possui um alto nível de ética & 3 & 3 & 3 & 3 \\
\hline Essa carreira oferece um grande potencial de crescimento para mulheres & 4 & 1 & 2 & 3 \\
\hline Essa carreira proporciona uma boa vida familiar & 2 & 1 & 2 & 2 \\
\hline Esse profissional possui uma grande habilidade com números & 1 & 1 & 2 & 2 \\
\hline
\end{tabular}

Observa-se que nos 24 atributos há pouca variação nas diferenças de avaliação entre os docentes dos 4 países. Tanto entre as questões em que a profissão é colocada entre as últimas posições, como entre as que ela é considerada como principal, como a habilidade com números (quantitativa) e de não ter uma vida estressante no trabalho, podendo ter uma vida familiar melhor. De maneira geral percebe-se que apenas os professores do Japão tiveram uma avaliação um pouco melhor da profissão, comparando-se com as outras três profissões analisadas.

A seguir são apresentadas as análises das percepções da profissão contábil a partir das variáveis de controle. Estas análises não são apresentadas nos estudos anteriores prévios, e foram inseridas com o objetivo de melhor compreender as avaliações sobre a profissão, sendo elas proximidade com a profissão (amigos e familiares), e tipo de instituição que leciona (pública/privada).

Conforme já exposto, a primeira das variáveis de controle foi sobre ter algum tipo de proximidade, familiar ou de amizade com profissionais da área contábil. As respostas indicaram que $42,9 \%$ dos respondentes tinham algum tipo de proximidade.

A tabela 5 demonstra que dos 24 (vinte e quatro) atributos, 18(treze) obtiveram notas maiores pelos professores de ensino médio que não possuem nenhum tipo de contato com profissionais da área contábil, enquanto 11(onze) atributos foram cotados com notas maiores por professores que têm algum tipo de contato com profissionais da área contábil.

Cabe, porém, ressaltar que o teste de Mann-Whitney apresentou em apenas 4 questões diferenças significativas. Em todas a percepção de quem não tem parente ligado a profissão contábil é maior. Em 3 delas, com ligação indireta com questões de status da profissão, os que não conhecem tem percepção melhor (Status na sociedade, carreira para melhores alunos e bom estilos de vida). Já em relação a necessidade de se fazer muitas horas extras e trabalho de fim de semana, os professores com parentes ligados à área de contabilidade tem menor concordância deste tipo de necessidade no profissional contador.

Analisando-se a mesma variável de controle, mas agora para a nota dada para a indicação da carreira de contador para seus alunos, encontrou-se uma nota média 8,11 para os que tinham alguma ligação com a profissão e 6,89 para o que não tinha. Apesar da diferença de 1,22 pontos o teste de Mann-Whitney não apresentou diferença estatística de avaliação entre os dois grupos.

Tabela 5- Contato com profissionais da área contábil

\begin{tabular}{|l|c|c|c|}
\hline & $\underline{\text { Não }}$ & $\underline{\text { Sim }}$ & $\begin{array}{c}\text { Diferenca } \\
\text { Significativa }\end{array}$ \\
\hline Esse profissional possui um alto status na sociedade & 2,47 & 1,92 & $*$ \\
\hline Esse profissional é essencial para a sociedade & 3,31 & 3,54 & \\
\hline Esse profissional ocupa uma posição de poder na sociedade & 2,33 & 2,00 & \\
\hline Esse profissional ocupa uma posição de glamour/destaque na sociedade & 2,24 & 2,00 & \\
\hline
\end{tabular}




\section{PERCEPÇÃO SOBRE A CARREIRA DE CONTABILIDADE SOB A ÓTICA DE PROFESSORES DO ENSINO MÉDIO}

\begin{tabular}{|c|c|c|c|}
\hline Essa carreira oferece potencial para o profissional ganhar muito dinheiro & 2,80 & 2,62 & \\
\hline O candidato encontra muita dificuldade para ingressar nessa carreira & 2,29 & 1,77 & \\
\hline Essa carreira oferece ótimas oportunidades de trabalho & 2,77 & 2,86 & \\
\hline Essa carreira oferece um grande potencial de crescimento ao profissional & 3,08 & 3,00 & \\
\hline Essa carreira oferece um grande potencial de crescimento para mulheres & 3,08 & 3,00 & \\
\hline Essa carreira é indicada para os melhores alunos & 2,65 & 2,15 & $*$ \\
\hline Esse profissional possui um alto nível de ética & 2,90 & 2,54 & \\
\hline Essa carreira é dominada por homens & 2,84 & 2,69 & \\
\hline O trabalho nessa profissão é muito desafiante & 2,61 & 2,92 & \\
\hline Esse profissional interage bastante com outras pessoas & 3,06 & 2,77 & \\
\hline Essa carreira proporciona uma grande satisfação na realização dos trabalhos & 3,22 & 2,77 & \\
\hline Esse profissional está propenso a cometer ações fraudulentas & 3,06 & 3,00 & \\
\hline Esse profissional possui uma grande habilidade de comunicação & 2,92 & 2,85 & \\
\hline Esse profissional possui uma grande habilidade para resolver problemas & 3,39 & 3,31 & \\
\hline Esse profissional possui uma grande habilidade com números & 3,90 & 3,92 & \\
\hline Essa carreira proporciona um bom estilo de vida & 2,98 & 2,54 & * \\
\hline Essa carreira proporciona uma boa vida familiar & 3,27 & 3,38 & \\
\hline $\begin{array}{l}\text { Essa carreira exige muitas horas de trabalho, tendo o profissional que fazer } \\
\text { horas extras, trabalhar de fim de semana, etc... }\end{array}$ & 3,00 & 2,23 & $*$ \\
\hline Essa carreira oferece estabilidade no emprego & 2,94 & 2,69 & \\
\hline O trabalho desempenhado nesta profissão é muito interessante & 3,06 & 3,31 & \\
\hline
\end{tabular}

Na tabela 6 são apresentadas as percepções comparativas entre docentes de escolas públicas e privadas, reforça-se que foram excluídos desta análise os docentes que atuam em ambas as áreas. Dentre os 24(vinte e quatro) atributos, somente em dois foram obtidos resultados maiores por professores de escolas particulares do que de escolas públicas (possibilidade de crescimento profissional e profissão dominada por homens).

Os demais 22 (vinte e dois) atributos possuíram resultados maiores com as respostas dos professores de escolas públicas. Observa-se que em 8 atributos foram observadas diferenças estatisticamente significativas de avaliação pelo teste de Mann-Whitney. As diferenças foram encontradas principalmente aos atributos ligados principalmente a questões de importância da profissão para a sociedade, com melhor avaliação de professores da rede pública, e de aspecto de habilidades dos profissionais também com melhor avaliação de docentes da rede pública.

Tabela 6- Segmento de atuação dos professores respondentes

\begin{tabular}{|l|c|c|c|}
\hline & $\underline{\text { Particular }}$ & $\underline{\text { Pública }}$ & $\underline{\underline{\text { Diferenca }}}$ \\
Significativa \\
\hline Esse profissional possui um alto status na sociedade & 1,85 & 2,55 & $*$ \\
\hline Esse profissional é essencial para a sociedade & 2,85 & 3,39 & $*$ \\
\hline Esse profissional ocupa uma posição de poder na sociedade & 2,23 & 2,3 & \\
\hline $\begin{array}{l}\text { Esse profissional ocupa uma posição de glamour/destaque na } \\
\text { sociedade }\end{array}$ & 2,08 & 2,25 & \\
\hline $\begin{array}{l}\text { Essa carreira oferece potencial para o profissional ganhar muito } \\
\text { dinheiro }\end{array}$ & 2,69 & 2,77 & \\
\hline O candidato encontra muita dificuldade para ingressar nessa carreira & 1,86 & 2,36 & \\
\hline Essa carreira oferece ótimas oportunidades de trabalho & 2,54 & 2,89 & \\
\hline $\begin{array}{l}\text { Essa carreira oferece um grande potencial de crescimento ao } \\
\text { profissional }\end{array}$ & 2,69 & 2,36 & \\
\hline
\end{tabular}




\begin{tabular}{|l|c|c|c|}
$\begin{array}{l}\text { Essa carreira oferece um grande potencial de crescimento para } \\
\text { mulheres }\end{array}$ & 2,54 & 3,16 & $*$ \\
\hline Essa carreira é indicada para os melhores alunos & 2 & 2,8 & $*$ \\
\hline Esse profissional possui um alto nível de ética & 2,46 & 2,89 & \\
\hline Essa carreira é dominada por homens & 3,23 & 2,66 & \\
\hline O trabalho nessa profissão é muito desafiante & 2,23 & 2,75 & \\
\hline Esse profissional interage bastante com outras pessoas & 2,77 & 3,09 & \\
\hline $\begin{array}{l}\text { Essa carreira proporciona uma grande satisfação na realização dos } \\
\text { trabalhos }\end{array}$ & 2,46 & 3,36 & $*$ \\
\hline Esse profissional está propenso a cometer ações fraudulentas & 2,85 & 3,14 & \\
\hline Esse profissional possui uma grande habilidade de comunicação & 2,23 & 3,07 & $*$ \\
\hline $\begin{array}{l}\text { Esse profissional possui uma grande habilidade para resolver } \\
\text { problemas }\end{array}$ & 3,08 & 3,48 & $*$ \\
\hline Esse profissional possui uma grande habilidade com números & 3,85 & 3,91 & \\
\hline Essa carreira proporciona um bom estilo de vida & 2,54 & 3,02 & $*$ \\
\hline Essa carreira proporciona uma boa vida familiar & 3,15 & 3,3 & \\
\hline $\begin{array}{l}\text { Essa carreira exige muitas horas de trabalho, tendo o profissional } \\
\text { que fazer horas extras, trabalhar de fim de semana, etc... }\end{array}$ & 2,31 & 3,05 & $*$ \\
\hline Essa carreira oferece estabilidade no emprego & 2,85 & 2,89 & \\
\hline O trabalho desempenhado nesta profissão é muito interessante & 2,62 & 3,2 & \\
\hline
\end{tabular}

Nas avaliações específicas observa-se então os professores de escolas privadas têm percepção, de maneira geral, mais negativa da profissão. Mas também é possível avaliar que a proximidade com a profissão, em diversos pontos, reduz um pouco a avaliação da profissão.

$\mathrm{Na}$ avaliação da nota para indicação da profissão de contador entre os professores de escolas públicas e privadas, encontrou-se uma nota média 7,64 para os professores de escola pública e 6,38 para os professores de escolas privadas. Estatisticamente também não foi encontrada diferença significativa de avaliação pelo teste de Mann-Whitney.

\section{CONCLUSÃO}

A proposta deste estudo foi o de avaliar se a percepção dos professores do ensino médio do Estado de São Paulo sobre a profissão contábil, seria semelhante à percepção sobre outras profissões como a engenharia, o direito e a medicina. $\mathrm{O}$ resultado encontrado foi de que as percepções deles não são semelhantes, sendo que na maioria dos atributos a percepção sobre a contabilidade foi pior do que a percepção sobre as outras três profissões.

Apesar de algumas diferenças da realidade brasileira, onde há um crescimento da profissão contábil, diferentemente de outros países, como os Estados Unidos, onde a profissão passa por declínio, o resultado foi semelhante aos estudos utilizados como base para este, exceto pelo estudo feito por Sugahara, Kurihara e Boland (2006) feito no Japão, onde a contabilidade foi pior que o direito e a medicina, mas melhor que a engenharia. Isso mostra que a contabilidade ainda é vista com o estereótipo de uma profissão monótona, rotineira, desinteressante, com pouca possibilidade de ganhos financeiros, com pouca oportunidade de crescimento, que não ocupa posição de destaque ou de poder na sociedade e que não seria indicada para os melhores alunos, além de indicarem também um perfil mais tímido e retraído do contador, similar em alguns pontos ao do engenheiro. Observa-se então, que na visão dos professores, a profissão é vista mais como uma ciência exata do que como uma ciência social aplicada, visão esta já percebida também nos estudos de Azevedo (2010), Miranda et al. (2012) e Miranda et al. (2013). 
Dessa forma, observa-se que é preciso criar meios para mostrar à sociedade que o contador faz é muito mais do que contas simplesmente, que o contador é muito mais do que aquele que apura impostos e faz a folha de pagamento. É preciso mostrar que o contador tem conhecimentos em direito e em outras áreas também, que o contador realiza não somente a escrituração contábil, mas pode exercer outras funções como a de auditoria e de controladoria. Esse é um papel que tanto os sindicatos da profissão como o Conselho Federal e Regionais de Contabilidade podem exercer.

A sociedade precisa perceber que o contador, mais do que dar suporte à tomada de decisão, é capaz de tomar decisões, de ocupar cargos de gerência ou diretoria. É preciso perceber também que para ser um contador é necessário mais do que habilidade com números, mas é fundamental a capacidade de análise e flexibilidade para lidar com mudanças no ambiente de trabalho (MCDOWALL, T.; JACKLING, B.; NATOLI, R. 2010).

O estudo apresenta a limitação de ter feito a análise apenas com professores do estado de São Paulo, ressalta-se, porém, que os estudos anteriores também utilizam amostras não amplas. Como o país tem uma grande diversidade cultural, sugere-se que o estudo seja ampliado, com a aplicação do questionário com professores de outras regiões do país. Entendese ainda que outros estudos devem fazer comparações com outras profissões, principalmente as correlatas a contabilidade, como a Administração e a Economia.

\section{ABSTRACT}

Studies show that high school teachers have meaningful participation in the students' decisionmaking regarding the choice of career. The studies of Sugahara, Kurihara and Boland (2006), Hardin, O'Bryan and Quirin (2000) and Wells and Fieger (2004) showed that teachers still do not understand the nature and importance of the accounting profession. This study aimed to analyze the perception of high school teachers in Brazil about the accounting career compared to careers in medicine, engineering and law, as well as made in previous studies. The study was conducted through a survey, adapted from previous studies to measure the perception of high school teachers in Brazil. Based on comparison with other professions accounting had the lowest score, confirming the results already found in previous studies.

Keywords: Secondary school teachers' perceptions, students' career and major choice, accounting profession,

\section{REFERÊNCIAS}

ALBRETCH, S. e SACK, R. Accounting Education: Charting a course through a perilous future, Accounting Education Series, American Accounting Association, v.16, 2000.

AZEVEDO, R. F. L. A percepção pública sobre os contadores: bem ou mal na foto?. Dissertação (Mestrado em Controladoria e Contabilidade) Faculdade de Economia, Administração e Contabilidade da Universidade de São Paulo, São Paulo, 2010.

BYRNE, M.; WILLIS, P. Irish secondary students' perceptions of the work of an accountant and the accounting profession, Accounting Education: an international journal, 14(4), 367381., 2005

CALLEGARO, M.; MANFREDA, K.L.; VEHOVAR, V. Websurvey Methodology. Thousand Oaks:SAGE Publications, 2015 
COLEMAN, M.; KREUZE, J.; LANGSAM, S. The New Scarlet Letter: Student Perceptions of the Accounting Profession After Enron, Journal of Education for Business, 79, pp. 134141,2004

COSTA, L. V. A relação entre a percepção de sucesso na carreira e o comprometimento organizacional: Um estudo entre professores de universidades privadas selecionadas da Grande São Paulo. Tese (Doutorado em Administração) Faculdade de Economia, Administração e Contabilidade da Universidade de São Paulo, São Paulo, 2010.

CONSELHO FEDERAL DE CONTABILIDADE. Profissionais e Escritórios Ativos. Disponível em: <http://portalcfc.org.br/coordenadorias/registro/cadastro/quantos_somos/>, Acesso em: outubro 2018.

HARDIN, J. R.; O'BRYAN, D.; QUIRIN, J.J.; Accounting versus engineering, law, and medicine: perceptions of influential high school teachers, Advances in Accounting, 17, pp. 205-220, 2000.

HUNT, S.C.; FALGIANI, A.A.; INTRIERI, R.C. The Nature and origins of students' perceptions of accountants. Journal of Education for Business. v. 79, n.3, p. 142-148, 2004.

INTERNATIONAL FEDERATION OF ACCOUTANTS, Organization Overview. Disponível em: < http://www.ifac.org/about-ifac/organization-overview>. Acesso em maio 2018.

INSTITUTO NACIONAL DE ESTUDOS E PESQUISAS EDUCACIONAIS ANÍSIO TEIXEIRA (INEP), Notas estatísticas: Censo do Ensino Superior 2016. Disponível em: < http://download.inep.gov.br/educacao_superior/censo_superior/documentos/2016/Notas_Estat isticas_Censo_Superior_2016.pdf > Acesso em: agosto 2018

MCDOWALL, T.; JACKLING, B.; NATOLI, R. Are we there yet? Changing Perceptions of Accounting as a Career Choice. In: AFAANZ Conference, Christchurch-NZ, 2010.

MIRANDA, C.S.; ARAUJO, A.M.P.; MIRANDA, R.A.M. Percepções sobre o Ensino Superior de Contabilidade e o Mercado de Trabalho dos Contadores: Uma Avaliação da População com Curso Superior Completo ou em Curso. In: $12^{\circ}$ Congresso USP de Controladoria e Contabilidade, São Paulo, 2012

MIRANDA, C.S.; MIRANDA, R.A.M.; ARAUJO, A.M.P.; Percepções dos estudantes do ensino médio sobre o curso de ciências contábeis e as atividades do profissional contador.

Revista de Gestão, Finanças e Contabilidade, v. 3, p. 17-35, 2013

PEKDEMIR, I.; PEKDEMIR, R. High School Teachers' Perceptions and Opinions on Professional Accountants: The Turkey Case, MPRA Paper, 2010.

SUGAHARA, S.; KURIHARA, O.; BOLAND, G. Japanese Secondary School Teachers' Perceptions of the Accounting Profession, Accounting Education: an international journal, 15, pp. 405-418, 2006.

WELLS, P.K.; FIEGER, P. Accounting: perceptions of influential high school teachers in the USA and NZ. Research Paper Series, New Zeland, 2005. 